\title{
Registro do Cultivo in vitro de Phyllachora torrendiella e Sphaerodothis acrocomie, Agentes Causais das Lixas do Coqueiro
}

\author{
Virgínia C. de Oliveira*, Edna C. Leal ${ }^{1}$ \& Jefferson L. da S. Costa ${ }^{2 *}$ \\ 1,2Embrapa Tabuleiros Costeiros, Cx. Postal 44, CEP 49001-970, Aracaju-SE, fax: (079) 226-1369, e-mail: \\ jcosta@cpatc.embrapa.br
}

(Aceito para publicação em 09/10/2003)

Autor para correspondência: Jefferson Luis da Silva Costa

\begin{abstract}
In vitro growth of Phyllachora torrendiella and Sphaerodothis acrocomie, causal agents of coconut scab wart

This is first report of mycelial growth of the Phyllachora

torrendiella and Sphaerodothis acrocomie causal agents of small and large warts on cononut (Cocos nucifera) in completely artificial media.
\end{abstract}

Dentre os principais problemas que limitam a produção do coco (Cocos nucifera L.) no Brasil estão as doenças foliares causadas por Phyllachora torrendiella (Batista) Subileau, (Catacauma torrendiella Batista) (lixa pequena) e Sphaerodothis acrocomiae (Montagne) von Ax \& Muller (Coccostroma palmicola Speg.) von Arx \& Muller (lixa grande) (Renard, J. L, Paris: IRHO, 1988) responsáveis pela redução de até $50 \%$ do potencial produtivo da cultura (Subileau, et al. Mycotaxon, 49:175-185. 1993). Por serem parasitas obrigatórios, esses fungos ainda não haviam sido cultivados em meio artificial e, conseqüentemente, pouco se conhece sobre sua variabilidade. Neste trabalho testou-se o crescimento de $P$. torrendiella e S. acrocomiae em um meio artificial “completo", o qual já gerou resultados positivos em trabalhos com outros patógenos parasitas obrigatórios agentes causais de ferrugens e carvões (Holliday, Handbook of Genetics. 1:575-595. 1974). Para tanto, folhas infetadas do coqueiro com sintomas de lixa grande e pequena foram coletadas dos genótipos Anão Verde e Anão Vermelho depositados no banco de germoplasma da Embrapa Tabuleiros Costeiros. Com auxílio de um microscópio estereoscópio, ascósporos individuais dos fungos foram retirados de estromas e dispersos sobre ágar-água (A-A). Em seguida blocos de A-A contendo um único ascósporo foram transferidos para erlenmeyers de $150 \mathrm{ml}$ com o meio de cultura completo contendo os seguintes componentes: glucose $(0,5 \%)$ tiamina $(0.1 \mu \mathrm{g} / \mathrm{ml})$, riboflavina $(0,05 \mu \mathrm{g} / \mathrm{ml})$, piridoxina $(0,05 \mu \mathrm{g} /$ $\mathrm{ml})$, pantotenato de cálcio $(0,2 \mu \mathrm{g} / \mathrm{ml})$, inositol $(0,4 \mu \mathrm{g} / \mathrm{ml})$, ácido nicotínico $(0,2 \mu \mathrm{g} / \mathrm{ml})$, elementos essenciais (Ryan, et al., American, Journal Botanical. 30:784-799. 1943) e solução de sais (Holliday, Handbook of Genetics. 1: 575-595. 1974). O pH final foi ajustado alternativamente para 3,0 e 7,0. Estes isolados foram agitados por 15 dias a $135 \mathrm{rpm}$ à $25 \pm 2{ }^{\circ} \mathrm{C}$. A germinação dos ascósporos ocorreu entre dez e 15 dias em uma taxa de $25 \%$ de sucesso, em ambos os $\mathrm{pH}$ gerando intensa produção

*Bolsistas do CNPq miceliogênica (Figuras 1 A e 1B), sendo este o primeiro registro de cultivo in vitro destes patógenos. O S. acrocomie produziu uma massa miceliogênica disforme de cor branca (Figura 1 B) e o $P$. torrendiella produziu uma massa miceliogênica homogênea predominantemente de cor bege claro (Figura 1 A). O micélio desenvolvido foi colocado sobre lâminas em gotas de lactofenol, recoberto por lamínulas e, fotodocumentado em um microscópio Kodo Digital em aumento de 200 a 1000 x (Figuras 1 A1 e 1 B2). A possibilidade de cultivar estes patógenos in vitro permitirá o aprimoramento de seu conhecimento e o estudo de sua variabilidade genética através de técnicas moleculares.

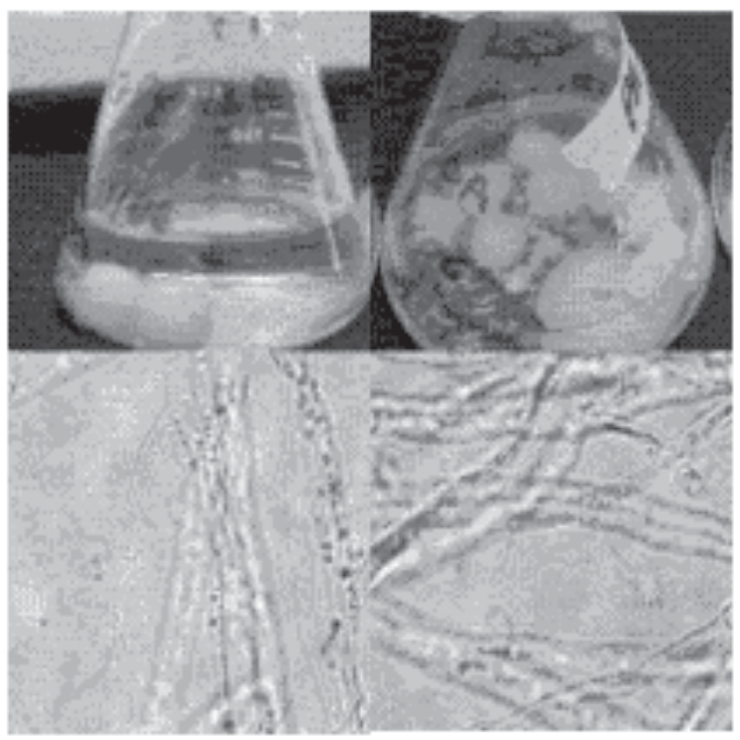

FIG. 1 - Cultivo de Phyllachora torrendiella (A) e Sphaerodothis acrocomie (B) em meio completo. (A1 - B2) Hifas de P. torrendiella e $S$. acrocomie (aumento de $1000 \mathrm{x}$ ), produzidas em meio líquido. 